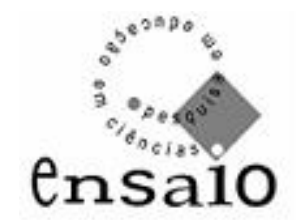

Vol. 10 no. 1 jun. 2008

\title{
Um olhar sobre a experimentação na escola primária francesa ${ }^{1}$
}

\author{
One to look at on the experimentation in the French primary school
}

Maryline Coquidé2

\begin{abstract}
Resumo
O objetivo desse artigo é discutir as competências profissionais exigidas para a aplicação de experiências em aulas de ciências tanto na escola primária como no ensino médio. Os professores salientam a importância de experiências no ensino de ciência, mas algumas investigações testemunham seu desagrado em conduzi-las, e suas proposições exprimem as dificuldades de propor alternativas aos seus métodos pedagógicos de intervenção. Sob um olhar mais atento, o consenso dos professores sobre a importância da "experimentação", para a aprendizagem em ciência parece apenas aparente. Por isso, é essencial analisar as formas e as funções de experiências no domínio do ensino de ciências, esclarecer e discutir os seus problemas educacionais.
\end{abstract}

Palavras chaves: experimentação, ensino de ciências, formação de professores.

\begin{abstract}
This article aims to help clarify the professional skills required for the experiences lessons at primary school as a secondary education. Teachers willingly stressed the importance of experiences in science education, but several investigations demonstrate their dismay to lead them, and their words express difficult to alternatives in their pedagogical methods of intervention. To look more closely, the consensus among players on the importance of "experiments" in science learning seems only apparent. So it is essential to analyzing the forms and functions of experiences in science education, clarify and discuss their educational issues.
\end{abstract}

Keywords: experiences, sciences teaching, teachers training

\footnotetext{
${ }^{1}$ Tradução: Prof. Dr. Paulo Cezar Santos Ventura (cefet-MG) pcventura@deii.cefet-mg.br

2 Professora Doutora Associada ao INRP e UMR STEF (ENS Cachan-INRP, França) Institut National de Recherche Pédagogique (França). maryline.coquide@inrp.fr.
} 


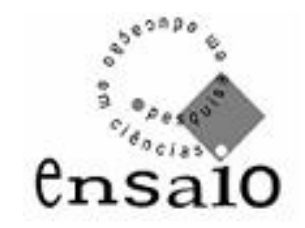

\section{- 1. Introdução}

Vol. 10 no. 1 jun. 2008

A operação «La main à la pâte »", lançada na França em 1996 com o objetivo de promover o ensino de ciências na escola primária (corresponde, no Brasil, às quatro primeiras séries do ensino fundamental), coloca em primeiro plano um procedimento pedagógico centrado sobre a exploração e experimentação de objetos e/ou fenômenos. Os alunos realizam as experiências propostas por eles mesmos, e as discutem visando compreender os aportes teóricos envolvidos nos procedimentos. Em consonância a tal proposta, o plano de renovação do ensino de ciências e tecnologia para a escola primária, adotado em junho de 2000, visou estimular os professores a articular o questionamento dos alunos sobre a natureza e os objetos, sob o olhar de uma metodologia construtivista de investigação, recomendando a experimentação em sala de aula. O novo programa do terceiro ciclo da escola (12 a 15 anos), centraliza-se em uma abordagem experimental, privilegiando, por exemplo, a descoberta da matéria e dos fenômenos físicos, em detrimento da realização de projetos tecnológicos.

No ensino médio, o trabalho prático (TP) e as atividades de experimentação podem ser considerados como um verdadeiro paradigma do ensino de ciências francês. Recentemente a avaliação das "competências experimentais" dos alunos em Física e Química se tornou obrigatória nos exames de conclusão da Educação Básica. Na Inglaterra, igualmente, as atividades experimentais e o laboratório escolar são de tal forma interligadas às práticas da educação científica escolar, que se torna difícil imaginar o modo de proceder em sua ausência, embora não se tenha chegado a um consenso sobre os seus efeitos (White, 1996). O laboratório, de fato, continua a ser pensado como detentor de um dos objetivos mais importantes da educação científica, e este é, talvez, uma principal razão de sua popularidade nos programas curriculares.

No entanto, sob o mesmo termo "abordagem experimental" estão agrupadas investigações que têm características muito diferentes para o estudo da vida e dos fenômenos físicos e químicos da matéria. Além disso, os conteúdos de ensino exigidos pelos programas são repletos de conceitos teóricos que não possuem uma base experimental, como é o caso do ensino da biologia e das geociências, nas escolas de ensino médio, em que os conteúdos nem sempre se adaptam à experimentação. Além disso, temos as dificuldades de entendimento institucional dos currículos que podem levar a flutuações muito rápidas nos programas das

\footnotetext{
${ }^{3}$ Conhecida no Brasil como “A mão na massa”.
} 


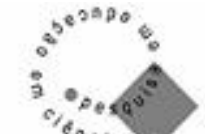 \\ ensalo}

Vol. 10 ํo. 1 jun. 2008

disciplinas. Por exemplo, a opção de "ciências experimentais", foi introduzida em 1993, nas turmas de ensino médio, opção científico, na França, e previa um currículo aberto, reservando longos períodos para facilitar a efetivação de práticas experimentais em ciências da vida para os estudantes. Por não ser obrigatória, essa opção desapareceu no início de 2000.

O objetivo desse artigo é apresentar uma revisão bibliográfica de pesquisas que problematizam a presença da experimentação em sala de aula e discutir suas implicações para a formação de professores para a escola primária.

\section{- 2. A experimentação em três contextos diferentes}

\section{- 2.10 contexto britânico}

As atividades experimentais, os trabalhos práticos e os laboratórios escolares têm despertado muitas pesquisas didáticas e pedagógicas. Em uma síntese, produzida a partir de diferentes estudos publicados em revistas anglofônicas, Lazarowitz e Tamir (1994) constatam uma constante repetição de dois pontos: os efeitos das atividades experimentais realizadas em sala de aula, e os fatores que facilitam o sucesso de aprendizagem nesses contextos. As atividades experimentais na escola podem, na verdade, assumir várias funções: inquérito, investigação, ilustração, descoberta ou até mesmo de aprendizagem sistemática. Essas funções têm criado tensões na comunidade de professores: debate em relação a apresentação ou não de uma metodologia de investigação; proposta da presença ou não de guias e orientações para os trabalhos práticos, presença ou não de mecanismos de avaliação e de exames, entre outras.

A visão atual dos professores sobre a natureza do ensino de ciência e as atividades experimentais é, na realidade, o resultado de uma longa história. Uma análise histórica do ensino das ciências na Grã-Bretanha, realizada por Nott (1996), retoma um questionário de 1963, e solicita a 700 professores que organizem dez objetivos possíveis para os trabalhos práticos. O autor observa que, em nenhum dos dez objetivos propostos, são usadas as expressões "descobrimento", “investigação”, ou "inquérito".

O questionário não incluía a idéia de fazer "ciência real" ou "se tornar um cientista", uma idéia que vai emergir uma década mais tarde. Segundo Nott foi o projeto Nuffield, cujo sucesso foi considerável nas décadas de 1960 e 1970, que estabeleceu o indutivismo nas ciências escolares. Mais tarde, nos anos 1970 e em grande parte dos anos 1980, aconteceram 


\section{ensa10}

Vol. 10 ํo. 1 jun. 2008

mudanças curriculares na direção de uma "ciência da atualidade", e tornou frágil a função da atividade experimental de observar fatos científicos e de ilustrar leis e teorias.

O último pilar presente nas revisões sobre a experimentação é a introdução, em 1989, no currículo nacional da Inglaterra e do País de Gales, de um módulo científico (Scientific Investigation ou Investigação Científica), dedicado à investigação dando ênfase a um rigoroso processo de validação. Essa introdução foi muito discutida pelos pesquisadores (Duggan \& Gott, 1995; Jenkins, 1995a, 1995b) na medida em que o quadro promovido, no âmbito desse módulo, foi considerado um modelo indutivista da atividade científica baseada no controle de variáveis, abrangendo três pontos: 1 . previsão e emissão de hipóteses; 2 . observação, medidas e manipulação de variáveis; 3. interpretação e avaliação de provas científicas.

A crítica a esse quadro indicava como aspecto negativo para a formação dos alunos a exclusão de grandes áreas científicas que não controlam variáveis, como a ecologia, a astronomia, ou a geologia. Em decorrência disso, desde 1994, o currículo de ciências inglês utiliza então o novo título da Ciência de Exploração (Exploration of Science) substituindo "variáveis" por "fatores", e defende uma estrutura menos rígida de validação.

De acordo com Nott, as duas principais funções do laboratório escolar, na GrãBretanha, são atualmente a criação e a recriação de conhecimentos e métodos científicos. Mas quais são as funções que lhes são atribuídos pelos professores?

\section{- $\quad 2.2 \mathrm{E}$ o que pensam os professores do ensino médio no contexto europeu?}

As percepções dos professores do ensino médio fazem parte, também, das dificuldades de pensar a experimentação para a escola primária. Assim, um estudo realizado a nível europeu, com muitos professores ciência, sublinhou, mais uma vez, a ausência de acordo sobre os objetivos atribuídos ao trabalho prático no ensino médio (Séré, 1998). Uma análise dos roteiros distribuídos aos estudantes para guiar os seus trabalhos práticos nos laboratórios escolares mostra que, seja qual for o país e a disciplina, há um "padrão" sobre tarefas que lhes são solicitadas. Assim, por exemplo, 90\% dos 55 roteiros de trabalhos práticos de física analisados exigem dos estudantes o estabelecimento de relações entre grandezas, e menos de 10\%, teste de uma previsão ou escolha de uma entre várias explicações possíveis de um fenômeno. Parece que o trabalho prático considerado usual solicita pouco aos estudantes a construir relações entre os conceitos, princípios e objetos físicos. 


\section{ensaio}

Vol. 10 ํo. 1 jun. 2008

No contexto francês, destacamos de nossas pesquisas os comentários dos professores de ciências da vida e da terra, que aplicaram a opção da ciência experimental para suas turmas ${ }^{4}$. Apesar desses professores entrevistados explicitarem uma satisfação global sobre o desenvolvimento de atividades experimentais em módulos de tempo de até um mês de observação, eles também abordam diversos problemas. Além das questões institucionais e materiais, para eles é visto como um desafio promover práticas experimentais de forma autônoma junto aos estudantes nesta opção. Eles revelam uma constante valorização do "método científico" como “a abordagem experimental” (Orlandi, 1991; Coquidé, 1998). Outra investigação sobre as práticas de professores de física e de química, nesse mesmo contexto, mostra o domínio de uma “abordagem científica reconstruída” onde há ainda um domínio da seqüência de observar, emitir hipótese e provar alguma coisa (Saint-Georges, 1997).

Apesar da insistência nas dificuldades em desenvolver as atividades experimentais, os propósitos explicitados pelos professores refletem um interesse didático na experimentação, notadamente no ensino de biologia. Há uma expectativa de que os estudantes participem, cada vez e ao mesmo tempo, de uma elaboração teórica e de uma validação empírica, com um pequeno espaço reservado à investigação. Essa prática sincrética, que evita escolher entre a teoria e a experimentação, concebe a atividade experimental de sala de aula ao mesmo tempo como um procedimento de apresentação de saberes e como treinamento de certas abordagens empíricas - sem dar destaque à nenhuma delas - e permite combinar pragmaticamente restrições múltiplas, da qual o tempo escolar é a menor delas. Mas não é esse sincretismo de múltiplos objetivos para a atividade experimental que coloca os professores em dificuldade? E, não é isso que está presente, há mais de um século, nas prescrições oficiais francesas?

“O ensino de ciências compreende ao mesmo tempo saberes, conteúdo disciplinar e descoberta” (1991).

“ $O$ aluno constrói ativamente seu saber, adquire métodos e técnicas na elaboração e na condução (sozinho, em equipe ou coletivamente) de uma abordagem de investigação explicativa dos fenômenos estudados” (1992).

Resumidamente, parece-nos que tanto as percepções recolhidas dos professores quanto os textos institucionais e administrativos, valorizam as atividades experimentais, e apresentam justificativas que entremeiam objetivos de aquisição de uma “cientificidade” enquanto finalidade educativa e metodologia pedagógica. Mas, essa argumentação desenvolve uma

\footnotetext{
${ }^{4}$ N.T. referente ao trabalho experimental opcional nas turmas da opção de científico, première scientifique
} 


\section{ensaio}

Vol. 10 no. 1 jun. 2008

continuidade entre o empírico e essa "racionalidade científica”, afastada de toda dialética do processo educativo. Fica subentendido que é suficiente “fazer para compreender" e de "ver para provar”. Assim, consideramos importante discutir os significados epistemológicos da experimentação, para melhor repensar as formas e as funções das atividades experimentais na escola.

\section{- 2.3 Qual a percepção de professores das atividades experimentais na escola primária francesa?}

Vários estudos recolhem depoimentos de professores da educação básica, sobre as atividades experimentais, visando analisar as funções que eles lhes concedem. Em um deles, investigando a percepção dos professores sobre o desenvolvimento de atividades científicas na escola, várias contradições emergem das respostas (Cantor, 1996). Por exemplo, os professores exprimem as palavras "observar", "experiência" e "questionar" quando eles enunciam os objetivos prioritários da execução dessas atividades, mas "os livros" e "a imprensa" são os suportes de ensino por eles citados com mais freqüência. Comparando essas aparentes contradições, tomamos como pressuposto que essa é proveniente das dificuldades vivenciadas pelos professores em colocar em prática um modelo de atividade experimental aparentemente ligado a uma certa concepção de atividade científica.

Em outro contexto de pesquisa, realizamos entrevistas com professores iniciantes nas escolas primárias, e nelas encontramos refletidos os vários medos, apreensões e as dificuldades enfrentadas no desenvolvimento de atividades experimentais em sala de aula (Coquidé, 2001). Muitas são as dificuldades práticas mencionadas, tais como a carência de equipamentos, os problemas locais, por exemplo a sala de aula não possuir um ponto de água. Eles descrevem uma espécie de "pedagogia Emmaüs"5.

"Há muitas coisas que temos visto na IUFM", mas que parece difícil de alcançar na sala de aula. Eu tinha trabalhado com sal, com a evaporação de água, sal marinho... Havia abundância de coisas para fazer, mas eu não sei como se pode aplicar em sala de aula ".

\footnotetext{
${ }^{5}$ N T. Associação criada em 1953 oriunda do movimento de solidariedade «Emmaüs » de Abbé Pierre que visava o acolhimento aos atingidos pelos confllitos da Segunda Guerra Mundial. www.emmaus-france.org

${ }^{6}$ N.T IUFM. Institut de Formation de Maître. Centro de formação onde os licenciandos concluem a formação pedagógica e os estágios supervisionados.
} 


\section{ensaio}

Vol. 10 no. 1 jun. 2008

"Para a mecânica como engrenagens, não há nada..., para a eletricidade, não há nada..., e tudo é assim"!

Os professores citam principalmente os pontos relativos às dificuldades pedagógicas, de organização educacional, gestão de classe, liderança e gestão do tempo escolar para que as atividades experimentais sejam cumpridas. Nesta categoria de dificuldades, já descritas e analisadas por Simone Baillauquès (1993) denominada de "a chegada abrupta" se refere às insuficiências de conhecimentos profissionais necessários ao exercício da profissão:

"Eu precisei de tempo... eu não sabia por onde começar, quais as medidas a adotar, quais progressões aprovar hoje ainda... "

"O que me incomoda é que todas as crianças não sejam atentas, eu tive dificuldade de captar a atenção de todas as crianças".

Problemas de tempo, sobretudo aquele necessário para a preparação das atividades científicas e técnicas, são muitas vezes citadas:

"Por enquanto, muitas vezes me sinto trabalhando dentro da urgência e de nem sempre tenho tempo de aprofundar nada", "para mim, esta é realmente uma questão de tempo".

As falas dos professores das escolas primárias sobre as funções da atividade experimental escolar parecem, na verdade, heterogêneas. Se elas apresentam a importância da "experiência", esse termo abrange um conjunto diverso de práticas e reflete uma série de ambigüidades. A partir de nossas pesquisas sistematizamos que, para os professores experimentar é:

1. observar, ou tudo que necessita de um observação;

2. manipular;

3. estar procurando, ou procurar;

4. provar e demonstrar.

A maior parte das vezes, por isso, todas as atividades são designadas pelo termo "experiência", quer manipulação concreta, atividades exploratórias de observação, verdadeiras demonstrações ou experiências reais. A idéia é muito presente na justificativa de uma experiência de "destaque". Trata-se essencialmente de "mostrar" (por exemplo, a natureza de um produto através de reagentes) ou de "identificar" um objeto ou fenômeno (Flageul \& Coquidé, 1999). 


\section{ensa10}

Vol. 10 ํo. 1 jun. 2008

Além disso, os aspectos práticos, sempre majoritários nas respostas, representam um importante obstáculo na concepção do que talvez seja um experimento. Eles podem esconder os papéis do raciocínio e da criatividade que são essenciais na emissão de hipóteses ou o desenvolvimento de procedimentos experimentais. Um núcleo central da maioria das respostas funciona sobre uma oposição entre, por um lado, o raciocínio e a construção intelectual, e de outro a manipulação de uma realidade física. Esta polarização parece refletir outras concepções dualistas baseadas em oposições como prática e teoria, concreto e abstrato, indução e dedução... Enfim, é a abordagem empiricista que é valorizada, com prioridade para os aspectos práticos e a experiência concreta. As dimensões do raciocínio ou do ensaio de idéias permanecem, no entanto, mal representados.

\section{- 3. O que pode ser então experimentar?}

As atividades experimentais sempre estabeleceram uma relação complexa com o mundo da realidade: entre relação com o mundo, e relação com o saber existe uma série de interações que mostram ao mesmo tempo o esforço de pensamento para atingir um grau de compreensão dos objetos e fenômenos. Temos que considerar também que há uma resistência do real que obriga o pensamento a se modificar. Isso justifica a necessidade pedagógica do “ser concreto” adaptar-se ao “colocar a abstração” como argumenta Bachelard (1934). Essa dialética entre o empírico e a razão é representada pelo método desenvolvido para poder articular o pensamento e a ação, através do raciocínio, da observação e da experiência.

\section{- 3.1 A polissemia da palavra "experimentar"}

A polissemia da palavra experimentar pode levar a uma confusão sobre as missões educativas. Destacamos duas significações sensivelmente contrastadas, de acordo com uma visão de ter a experiência como acumulação empírica ou de fazer uma experiência como uma validação de uma hipótese. Em inglês há a disposição duas palavras diferentes: experience e experiment. Então, trata-se de multiplicar as referências empíricas ou bem atingir um papel de demonstração dentro de uma construção intelectual? Se quisermos designar a experiência vivida, no sentido filosófico da prova, a prática do ensaio e do erro empírico, faremos, por exemplo, os alunos vivenciarem um conjunto de situações para fundir um referencial compartilhado na sala de aula. Se desejarmos designar a experimentação do cientista, no 


\section{ensalo}

Vol. 10 no. 1 jun. 2008

sentido da busca de evidências e provas de uma proposição, desenvolveremos protocolos escolhidos entre as abordagens específicas de validação de modelos teóricos.

Podemos revisitar a distinção estabelecida pelos estudos de história das ciências para as palavras "experientia" e "experimentum”. Historicamente, a "experientia” acorda crédito aos fatos observáveis e às decorrentes acumulações comprobatórias, pois a experiência era "ligada ao valor reconhecido da demonstração visual para a confirmação de verdades científicas: fazer ver e a rever, era fazer compreender, e a repetição valia como demonstração suplementar” (Salomon-Bayet, 1978). O “experimentum”, tal como ele aparece entre os séculos XVI e XIX, representa, ao contrário da experiência, uma prática não natural. Ela conduz a colocar condições consideradas como singulares e artificiais, ultrapassa as aparências e as evidências primeiras, e visa estabelecer as provas para fundar novos conceitos. Isso conduz a construir situações calculadas e a usar novas formas de raciocínio: da confrontação de hipóteses a testes de verificação. Como o analisa bem Bachelard (1938) :

"É tomando consciência dessa revolução da cidade do saber que podemos compreender verdadeiramente o poder da formação psicológica do pensamento científico, e que apreciaremos a distância do empirismo passivo e registrado ao empirismo ativo e pensado"

Na reconstituição da história da “prova experimental” presente em relatórios científicos, Licoppe (1996) estabelece a percepção que possuíam pensadores do século XVII sobre a característica regular ou caprichosa dos fenômenos, e o poder de controle exercido pelos instrumentos. Desde então, o experimentum desloca a ciência para o laboratório de pesquisa. As observações e as “experiências” se instrumentalizaram com práticas que se tornaram cada vez mais difíceis para os “amadores”, e também com procedimentos e resultados experimentais mais difíceis de comunicar. Os pesquisadores precisaram então desevolver uma explanação indireta de suas ações, pois o público e outros pensadores não acompanhavam mais diretamente suas experiências como destaca (Licoppe, 1996):

“As estratégias persuasivas se revestem de cada vez mais importância para os atores preocupados em fundar a verdade de fatos e de fenômenos novos, em um campo de práticas que apenas se deslocavam do cotidiano, que a adesão aos efeitos assim relatados se operavam muitas vezes a reboque do senso comum"

Licoppe descreve a lenta construção de uma retórica particular, que visa transmitir o controle do savoir-faire empírico: uma retórica fundamentada na reprodução de práticas 
Vol. 10 no. 1 jun. 2008

experimentais, e destinada a convencer essencialmente os pares. Em conseqüência, diferentemente do restante da sociedade, os pensadores não se interessam mais em fatos curiosos ou úteis, mas desejam construir "fatos exatos”. Estabelecer uma prova experimental, é então construir o controle estrito e a reprodução da experiência, possível apenas através da evolução de práticas materiais colaborativas. Três indicadores do desenvolvimento dessa retórica experimental podem ser destacados: a construção de fatos exatos pelo controle instrumental, a reprodutibilidade de práticas empíricas e a convicção dos pares.

\section{- $\quad 3.2$ Perspectiva empírica e perspectiva experimental}

A passagem ao laboratório e à instrumentalização deslocou a investigação científica do natural ao artificial, da coleta de percepções à construção de protocolos, do relato de fatos curiosos e úteis à validação de fatos exatos, com a elaboração relatórios experimentais destinados a convencer os pares, e com uma ação recíproca de pesquisa e de técnicas. Não se trata mais de recensear os fenômenos naturais, mas de construir fatos experimentais. Uma análise epistemológica conduz ao quadro 1 que lista as diferentes dimensões em jogo na postura empírica comparada à experimental.

Essas dimensões agrupadas representam o que poderíamos qualificar de “ideário” de uma postura empírica e experimental, cada uma delas tendo uma forma de escrita específica.

\begin{tabular}{|l|l|}
\hline \multicolumn{1}{|c|}{ Perspectiva empírica } & \multicolumn{1}{c|}{ Perspectiva experimental } \\
\hline - A natureza e as práticas sociotécnicas & - Uma prática sociotécnica de laboratório \\
- O vivido e a relação prática aos objetos, à descrição & - O recurso e a relação indireta aos objetos, à criação de \\
de fenômenos, & fenômenos, \\
- O familiar e o natural & - O artificial \\
- Esforço de categorização. & - Esforço de análise, de objetivação e de mensuração. \\
- Coleta de observações e manipulações & - Experimentação \\
- Dados fora de um quadro teórico & - Dados dentro de um quadro teórico \\
- Saberes e práticas empíricas incluídas ou retiradas de & - Desenvolvimento de práticas empíricas reprodutíveis \\
práticas sociais & e aplicáveis \\
- Pesquisa de regularidades & - Pesquisa de invariantes \\
- Correlações empíricas & - Relações causais \\
- Fatos curiosos e úteis & - Fatos exatos e reprodutíveis \\
- Relato e descrição, receitas e fórmulas & - Relatórios experimentais \\
- Relato da experiência em forma de crônica & - Relato da experiência de forma metódica \\
\hline
\end{tabular}

Quadro 1: Perspectiva empírica e perspectiva experimental 


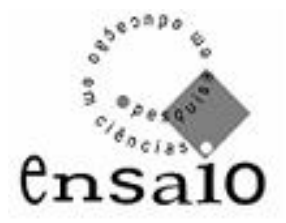

Vol. 10 no. 1 jun. 2008

\section{- $\quad 3.3$ A teoria da investigação}

Cada uma dessas dimensões possui uma coerência mais próxima seja de uma ajuda, seja de um obstáculo, à construção de um saber científico. Nós não buscamos estabelecer uma hierarquia entre essas duas perspectivas, mas melhor compreender a coerência de cada uma e analisar suas articulações em toda investigação. Todo processo de pesquisa necessita de momentos empíricos algumas vezes bem longos, pois o real não se deixa facilmente ser manipulado ou conceituado. Essa "resistência do real" conduziu a comunidade científica a articular abordagens de exploração e de validação e, a superar múltiplos desafios: intelectuais e técnicos, mas também éticos e sociais.

A filosofia pragmática inspirou Dewey (1938) no projeto de articular o conhecimento e a experiência em um contínuo da relação do homem ao mundo, do pensamento à ação, dos signos e dos símbolos ao pensamento. Rejeitando o dualismo em todas suas formas, ele propôs uma matriz de investigação (enquiry), integrando, ao mesmo tempo aspectos psicológicos e sociológicos. Não é ao aspecto técnico do método científico que ele faz referência, mas ao processo e ao modo em que as experiências são utilizadas, diferenciando o experencial do experimental. Ele nomeia de “situações” um ambiente físico e cultural, colocado a disposição do sujeito, isto é, um ambiente privilegiado e experenciado. O sujeito se coloca “em busca de” (em quête), uma vez que uma situação aparece em um momento indeterminado. A investigação (en quête, em busca de), para Dewey, aparece como uma abordagem orgânica e cultural de busca do sujeito pelo seu equilíbrio, em busca da solução da obscuridade de sua situação, em um momento preciso de sua história. A situação é “indeterminada” quando o sujeito se submete a ela e, ela se torna "problematizada” desde que o sujeito decida a reorientá-la e reorganizá-la. Dewey atribui o papel do experimental em um processo de investigação, não no sentido restrito de controle experimental científico, instrumentalizado e matematizado, mas no sentido amplo onde o "experimental” significa ao mesmo tempo "provar”, “colocar em prova” e “experenciar”, ou seja, uma continuidade entre o orgânico e cultural com a situação.

Bachelard, em sua perspectiva, propõe as concepções de forma opostas: a continuidade e a ancoragem positiva dentro do vivenciado no empirismo, ele opõe a descontinuidade e a dimensão polêmica da racionalidade. As perspectivas desses dois autores 


\section{8 \\ ensalo}

Vol. 10 ํo. 1 jun. 2008

são diferentes. Enquanto para Dewey o problema é concebido dentro do projeto tendo uma natureza psicológica, ele é então interior ao sujeito, para Bachelard ele tem uma natureza epistemológica e está posto pelo objeto.

«Antes de tudo, é necessário savber colocar os problemas. Os peoblemas não se apresentam por eles mesmos. É precisamente este sentido do problema que tornase a verdadeira marca do espírito científico. " (Bachelard, 1934).

Do ponto de vista didático, parece que na escola, a perspectiva empírica metódica e a empírica experimental crítica correspondem a episódios diferentes, que se articulam na mesma educação científica. A experimentação então, de nosso ponto de vista, possui uma tensão entre prudência e audácia, uma saída para a imaginação especulativa e uma constante submissão à experiência. As abordagens heurísticas, de convicção e de refutação se complementam na investigação experimental.

\section{- $3.4 \mathrm{O}$ trabalho com a prova e uma definição ampliada de experimentação}

Atualmente, a extraordinária potencia do cálculo e a análise de dados, ofertada pelas ferramentas de informática e de simulações autorizam o tratamento estatístico sobre uma massa enorme de dados, e facilita a lisibilidade de resultados experimentais. As ferramentas informatizadas reforçam a característica empírica e indutiva da pesquisa, e elas implicam em um novo tipo de experiência. Ao lugar de procurar uma pesquisa de causallidade simples, do tipo uma causa e um efeito, com uma experimentação que suprime a causa, os planos experimentais visam a coleta de dados para uma análise estatística e uma pesquisa de covariantes.

De outro lado, a experimentação não aparece mais exclusivamente como um teste ou prova para corroborar ou refutar uma hipótese, ela pode assim tomar-se a forma de aplicação teórica ou de um modelo. Lembremos que uma ciência como a biologia, é certamente uma ciência de laboratório, mas também uma ciência de trabalho de campo. O campo mobiliza tantas invenções e instrumentalizações sofisticadas quanto o laboratório experimental. Ele, contudo, não permite, como destacou Isabelle Stengers (1993), uma submissão e controle sistemáticos dos fenômenos. No laboratório, o cientista inventa os dispositivos que devem fornecer elementos para o julgamento da teoria. No campo, ele é menos juiz e mais investigador, para recolher os indícios e confronta-los à realidade e a suas elaborações teóricas. O emprego de modelos permite assim imaginar coletas de dados em ambientes 


\section{ensaio}

Vol. 10 ํo. 1 jun. 2008

outros que o laboratório. Nós assumimos, então, a definição ampliada de experiência científica proposta por Legay (1997) : «todo procedimento organizado de aquisição de informações que comporta, na perspectiva de um objetivo expresso, uma confrontação com a realidade ». Essa definição de experiência científica, em termos de «procedimentos úteis em vista de um certo objetivo», permite, de fato, incluir um número mais importante de formas de atividades experimentais. Não restrita ao laboratório, ela permite de ser aplicada às ciências de campo. A experiência, ampliada a procedimentos ativos de extração de informações do real, e emprego de modelos mostra bem que atualmente todas investigações científicas necessitam de interações complexas entre observar, comparar, experimentar e modelizar.

\section{- 4. Em busca de uma nova tensão}

A experimentação solicita uma ultrapassagem do sentido, um deslocamento de mãos e de inferências, ela necessita do estabelecimento de uma tensão entre o pensamento e a realidade que ela procura a conceituar e modelizar. Uma outra tensão é oriunda dos aspectos sociais, onde a necessidade da argumentação nos debates científicos, e do recurso da colocação em texto e da experimentação, aparecem como modos de convencimento dos pares. Os debates surgem primordialmente na negociação científica, com a elaboração da prova experimental e dos relatórios experimentais como elementos de convicção dos pares. Geralmente, é o trabalho coletivo dos «trabalhadores pela prova » segundo a expressão de Bachelard (1949), que produz a construção do fato científico.

A partir da investigação minuciosa efetuada em um laboratório de biologia, Latour et Woolgar (1979) apresentaram a importância das inscrições, lisibilidade, manipulações e primado das técnicas, na negociação científica. A construção de fatos científicos se refere, de fato, a um lento trabalho manual e prático no qual as inscrições são supercolocadas e os resultados conservados ou abandonados.

A análise histórica e epistemológica mostra que uma racionalidade experimental não pode jamais se reduzir ao uso de uma única lógica, mas exige a articulação de um sistema material e intelectual. Neles são importantes:

1. Materialidade dos dados e a instrumentalização;

2. Dinamismos nos diversos momentos: exploração e validação; empírico e experimental; 


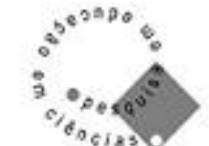 \\ ensa10}

Vol. 10 no. 1 jun. 2008

3. Múltiplos escritos: caderno de laboratório, relatos experimentais, inscrições diversas...

Os diferentes escritos que acompanham os episódios das diferentes abordagens têm funções específicas: escritos individuais ou de observadores, escritos para memorização, para ajudar a pensar, para comunicar ou convencer... A relação à escrita representa, de modo constante, um momento de transição fundamental na relação entre o experimental e o mundo.

A análise das formas contemporâneas da experiência, que integram de forma interativa a experimentação, a modelização e a operacionalizão de técnicas; a abordagem investigativa e a observação ativa conduz a se colocar em oposição às teorias dualistas que conservam a teoria e a prática em oposição e não em interação. As ciências experimentais, não podem conceber uma dualidade entre a relação com real, a elaboração teórica e suas aplicações. Essa concepção, no entanto, parece ainda presente no ensino, em particular na forma como os professores abordam os trabalhos práticos.

\section{- 4.1 Quais inquietações para a prática profissional dos professores?}

A tendência dos professores, na França, em privilegiar as concepções empiristas e positivistas das ciências e regularmente apontada nas pesquisas em didática das ciências (Johsua, 1989 ; Galiana, 1999). Essas concepções se caracterizam por uma insistência sobre a idéia da descoberta, considerando o saber uma construção tortuosa e onerosa, e sobre o qual há uma «submissão aos fatos », quando o conhecimento científico é antes de tudo crítico. Quanto às concepções positivistas, elas se traduzem na insistência de um respeito às etapas obrigatórias de um método, símbolo do rigor supostamente do raciocínio, quando esse o mesmo não é que uma componente entre outras da atividade científica.

A conjunção dessas duas posturas se traduz habitualmente no ensino por atividades que privilegiam a “colocação em evidência” de fenômenos e leis, que se apresentam depois como "naturais" decorrentes de operações reguladas, e que comportam o mito da "experiência crucial”. Ou então uma posição onde não há nenhuma evidência na ciência, pois ela avança graças às rupturas com o senso comum. Nessa posição, as abordagens não possuem nada de natural, pois elas supõem uma construção que não se impõe pela prova, pois a interpretação dos resultados resta muito grande. Contudo, o estabelecimento do resultado científico repousa 


\section{8 \\ ensa10}

Vol. 10 ํo. 1 jun. 2008

mais sobre os consensos entre os pesquisadores que unicamente sobre a pura lógica, e supõe um debate permanente no interior dessa comunidade.

A interpretação clássica que a pesquisa em educação tem apresentado para a ausência da experimentação na escola primária francesa, em geral, tem se pautado na resistência que os professores têm à mudança de suas práticas e, resumidamente, justificam essa ausência na atribuição de um déficit de formação. Porém essa justificativa parece insuficiente, uma vez que pesquisas junto aos professores, como de Nott et Wellington (1996), já apontavam que eles não são alheios às defasagens entre suas práticas. Acrescentamos que também discutem as exigências da promoção de atividades científicas autênticas e que os mesmo têm consciências da necessidade de uma abertura para as mudanças. Outras explicações são, então necessárias, pois as resistências sempre são indicadores de significação. Assim as pesquisas de Bomchil et Darley (1998) sugerem o uso implícito, pelos professores, de uma forma de silogismo investido. Segundo o autor, para o professor, « eu vejo que » funciona como a conseqüência de um raciocínio onde a premissa é o saber que ele que ensinar (a experiência sendo, para o professor, ilustrativa da noção). No entanto na cena didática, « eu vejo que » se torna a premissa, a experiência cuidadosamente escolhida toma o lugar de um argumento de saber que queremos ser adquirido dando sentido à prova. No lugar de uma « indução mole » que não prova nada, precisamos promover uma « dedução dura », que igualmente não prova nada, mas possui estimula mais uma relação investigativa com o conhecimento científico.

Podemos evocar uma diversidade de explicações, que intervêm em diferentes planos, mas que convergem para estabelecer uma economia didática já instalada na prática de ensino de ciências que conhecemos sendo marcada por:

1. Uma sobrevida « fóssil » do cientista do século XIX, hábil na manipulação de aparelhagens, confortando a imagem de sábio genial, visionário e desinteressado e contribuindo para o prestígio ideológico da ciência e do progresso científico;

2. Uma permanência de certas experiências prototípicas, que estão presentes nos livros didáticos desde um século e que funcionam como referências ritualizadas, julgadas indispensáveis para o percurso escolar além de qualquer valor formativo (por exemplo, para explicitar a fotossíntese mostrar a liberação de oxigênio ao iluminar folhas de plantas aquáticas); 


\section{ensaio}

Vol. 10 ํo. 1 jun. 2008

3. Posições identitárias e cooporativas, os trabalhos práticos aparecem como o que faz a especificidade do ensino de ciências experimentais, notadamente em comparação ao ensino das matemáticas e outras... sendo, por isso, justificado meios suplementares em materiais, espaços e grupos de alunos reduzidos;

4. Uma visão ingênua de uma nova educação, reificada em simples «método ativo » onde a manipulação seria a chave decisiva para a compreensão. Logo, um professor concreto e um aluno atuante se impõem como a mola principal da motivação, com o risco permanente de confrontar a atividade mental ao ativismo prático;

5. Uma deficiência de conceitos para pensar os problemas de aprendizagem em conformidade com os resultados atuais das pesquisas em domínios como da psicologia cognitiva e da didática das ciências.

Tais marcas representam um desafio para os pesquisadores de ensino de ciências. Há ainda um longo percurso para se estabelecer um diálogo efetivo entre as pesquisas e a prática profissional de professores das escolas primárias francesas.

\section{- Referências Bibliográficas}

BACHELARD Gaston. Le nouvel esprit scientifique. Paris: Alcan. 1934. (rééd. Puf, 1968).

BACHELARD Gaston. La formation de l'esprit scientifique. Paris: Vrin. 1938. (rééd. 1970).

BACHELARD Gaston. Le rationalisme appliqué. Paris: Puf. 1949

BAILLAUQUÈS Simone \& BREUSE Édouard. La première classe. Paris: Esf. 1993

BOMCHIL Simone \& DARLEY Bernard. L’enseignement des sciences expérimentales est-il vraiment inductiviste? Aste, 26, 1998. p. 85-108.

CANTOR Maryline. Les pratiques d'activités scientifiques : une enquête auprès d'instituteurs.

La formation initiale des professeurs des écoles en sciences et technologie. Paris: Inrp 1996. p. 56-60.

COQUIDÉ Maryline. Les pratiques expérimentales: propos d'enseignants et conceptions officielles. Aster, 26, 1998.p. 109-132. 


\section{ensaio}

Vol. 10 ํo. 1 jun. 2008

COQUIDÉ Maryline (coord.) Rapport de recherche Inrp/Iufm de Rouen: La main à la pâte, 1998-2001. Document interne Inrp. 2001

DEWEY John. Logique: la théorie de l'enquête. Paris: Puf .1938 .(rééd. 1993).

DUGGAN Sandra \& GOTT Richard. The place of investigations in practical work in the UK National Curriculum for Science. International Journal of Science Education, 17, n²: 1995. p.137-147.

FLAGEUL Roland \& COQUIDÉ Maryline. Conceptions d'étudiants professeurs des écoles sur l'expérimentation et obstacles corrélatifs à sa mise en œuvre à l'école élémentaire. Aster, 28, 1999. p. 33-56.

GALIANA Dominique. Problèmes didactiques posés par l'enseignement expérimental de la biologie dans les classes scientifiques des lycées, cas de la photosynthèse. Thèse de doctorat: Université Paris-Sud. 1999

JENKINS Edgar. Central policy and teacher response? Scientific investigation in the national curriculum of England and Wales. International Journal of Science Education 17, n²4, 1995a p.471-480.

JENKINS Edgar. When is a policy not a policy? School-based assessment of practical science at $16+$. International Journal of Science Education 17, n5. 1995b. p.555-563.

JOHSUA Samuel. Le rapport à l'expérimental dans la physique de l'enseignement secondaire. Aster, 8, 1989.p. 29-54.

LATOUR Bruno \& WOOLGAR Steve. La vie de laboratoire, la production de faits scientifiques. Paris: La Découverte. 1979. (traduction 1988).

LAZAROWITZ Reuven \& TAMIR Pinchas. Research on using Laboratory instruction in Science. Handboock of research on science teaching and learning. New York: Mac millan Publishing Company. 1994. p.94-128.

LEGAY Jean-Marie. L'expérience et le modèle. Un discours sur la méthode. Paris: Inra. 1997 LICOPPE Christian. La formation de la pratique scientifique: le discours de l'expérience en France et en Angleterre (1630-1820). Paris: La Découverte. 1996

NOTT Mick \& WELLINGTON Jerry. When the black box springs open : practical work in schools and the nature of science. International Journal of Science Education, 7. 1996. p.807818.

ORLANDI Éliane. Conceptions des enseignants sur la démarche expérimentale. Aster, 13, 1991. p.111-132. 


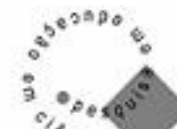 \\ ensaio}

Vol. 10 ํo. 1 jun. 2008

SALOMON-BAYET Claire. L’institution de la science et l'expérience du vivant. Paris: Flammarion. 1978

SÉRÉ Marie-Geneviève, coord. . Labwork in Science education. Final Report. Bruxelles: Commission européenne. 1998

WHITE Richard. The link between the laboratory and learning. International Journal of Science Education 18, n7. 1996.p. 761-774.

DATA DE RECEBIMENTO: 26/04/2007

DATA DE APROVAÇÃO: 19/12/2007

DATA DE VERSÃO FINAL: 26/06/2008

\section{Résumé:}

Les enseignants soulignent volontiers l'importance des expériences dans l'enseignement scientifique, mais plusieurs enquêtes témoignent de leur désarroi pour les conduire, et leurs propos expriment des difficultés à effectuer des choix alternatifs dans leurs modes d'intervention pédagogique. À y regarder de plus près, le consensus des acteurs sur l'importance des «expériences» dans un apprentissage scientifique ne semble qu’apparent. Aussi apparaît-il indispensable, en analysant les formes et les fonctions des expériences dans un enseignement scientifique, de clarifier et de débattre de leurs enjeux éducatifs. Il s'agit ainsi de contribuer à clarifier les compétences professionnelles nécessaires pour ces enseignements, à l'école primaire comme dans l'enseignement secondaire.

Mot clés: expérimentation, enseignement des sciences, formation des enseignants 